\title{
Preparation and Evaluation of Cabazitaxel-Loaded Bovine Serum Albumin Nanoparticles for Prostate Cancer
}

This article was published in the following Dove Press journal: International Journal of Nanomedicine

\author{
Zhong Wan ${ }^{1, *}$ \\ Fangyuan $\mathrm{Xie}^{2, *}$ \\ Liang Wang ${ }^{3}$ \\ Guoqing Zhang ${ }^{2}$ \\ Hai Zhang $\mathbb{( D}^{3}$ \\ 'Urologic Medical Center, Shanghai \\ General Hospital, Shanghai Jiao Tong \\ University School of Medicine, Shanghai \\ 200080, People's Republic of China; \\ ${ }^{2}$ Department of Pharmacy, Shanghai \\ Eastern Hepatobiliary Surgery Hospital, \\ Second Military Medical University, \\ Shanghai 200438, People's Republic of \\ China; ${ }^{3}$ Department of Pharmacy, \\ Shanghai First Maternity and Infant \\ Hospital, Tong Ji University School of \\ Medicine, Shanghai 201204, People's \\ Republic of China \\ *These authors contributed equally to \\ this work
}

\begin{abstract}
Purpose: Cabazitaxel (CBZ) is a new taxane-based antitumor drug approved by the FDA for the treatment of prostate cancer, especially for patients with advanced prostate cancer for whom docetaxel is ineffective or causes aggravation. However, Tween 80 injection can cause serious allergic reactions, and CBZ itself has strong toxicity, adverse reactions, and poor tumor selectivity, which greatly limits its clinical applications. Therefore, the CBZ-loaded bovine serum albumin nanoparticles (CBZ-BSA-Gd-NPs) were developed to overcome the allergenic response of Tween 80 and realize the integration of diagnosis and treatment.
\end{abstract}

Methods: CBZ-BSA-Gd-NPs were prepared by the biomineralization method. The characterization, magnetic resonance imaging (MRI), safety, and antitumor activity of the nanoparticles were evaluated in vitro and in vivo.

Results: The prepared nanoparticles were uniform in size $(166 \mathrm{~nm})$, with good MRI performance and stability over $24 \mathrm{~h}$. Compared with CBZ-Tween 80 injection, CBZ-BSAGd-NPs showed much lower hemolysis, similar tumor inhibition, and enhanced cellular uptake in vitro. The pharmacokinetic behavior of CBZ-BSA-Gd-NPs in rats showed that the retention time of the nanoparticles was prolonged, the clearance rate decreased, and the area under the drug-time curve increased. The distribution of CBZ-BSA-Gd-NPs in nude mice was characterized by UPLC-MS/MS and MRI, and the results showed that CBZ-BSAGd-NPs could effectively target tumor tissues with reduced distribution in the heart, liver, spleen, lungs, and kidneys compared with CBZ-Tween 80, which indicated that CBZ-BSAGd-NPs not only had a passive targeting effect on tumor tissue but also achieved the integration of diagnosis and treatment. In vivo, CBZ-BSA-Gd-NPs showed improved tumor inhibitory effect with a safer profile.

Conclusion: In summary, CBZ-BSA-Gd-NPs can serve as an effective therapeutic drug carrier to deliver CBZ into prostate cancer, and realize the integration of diagnosis and therapy.

Keywords: cabazitaxel, bovine serum albumin, nanoparticles, prostate cancer, magnetic resonance imaging, gadolinium

Department of Pharmacy, Shanghai

Eastern Hepatobiliary Surgery Hospital,

Second Military Medical University,

Shanghai 200438, People's Republic of

China

Tel/Fax +86-2I-8I87557|

Email guoqing_zhang9।@I26.com

Hai Zhang

Department of Pharmacy, Shanghai First Maternity and Infant Hospital, Tongji

University School of Medicine, Shanghai

201204, People's Republic of China

Tel/Fax +86 2I-2026I40I

Email zhxdks2005@I26.com

\section{Introduction}

Prostate cancer is a common male genitourinary tumor. Recently, the incidence rate has increased year over year, and is a serious threat to men's health. ${ }^{1}$ Endocrine therapy is effective in patients with early-stage prostate cancer, but after 14 to 30 months of median treatment, most patients will gradually progress to castration-resistant prostate cancer (CRPC), where endocrine therapy has small effects. $^{2}$ 
Cabazitaxel (CBZ) is a novel taxane antitumor drug approved by the FDA for the treatment of prostate cancer, especially for patients with CRPC. ${ }^{3,4}$ It is the 7.10-OH methyl etherification product of docetaxel and can diaplay an antitumor effect by interfering with the cellular microtubule network. ${ }^{5,6}$ Due to methyl etherification, it has a weaker affinity for P-glycoprotein than paclitaxel and docetaxel, so it has a stronger inhibitory effect on cancer cells that are tolerant to paclitaxel and docetaxel, especially for patients with metastatic prostate cancer for who docetaxel is ineffective or causes aggravation. ${ }^{7-10}$ In 2010, the FDA approved the marketing of CBZ injection developed by Sanofi combined with prednisone to treat patients with castration-resistant metastatic prostate cancer who had previously received a docetaxel-containing regimen. However, due to the poor water solubility of CBZ, the solubilizing agent Tween 80 was added to the clinical application of the injection, which may cause adverse reactions such as severe allergic reactions, including systemic rash/ erythema, hypotension, and bronchospasm. ${ }^{11-13}$ Additionally, the toxicity, adverse reactions and poor tumor selectivity of CBZ itself cause the clinical applications of CBZ to be extremely limited. ${ }^{14,15}$ Therefore, it is urgent to develop a new drug delivery system that can achieve high-efficiency and lowtoxicity therapeutic effects.

Nano-drug delivery systems, as carriers of antitumor drugs, can extend the half-life of the drugs in vivo, improve tumor targeting, and reduce toxicity. ${ }^{16-18}$ The materials of the nanodrug delivery system mainly include natural biodegradable and synthetic high molecular weight polymers. ${ }^{19}$ Among them, natural biodegradable nanocarriers are widely used due to their biodegradability, biocompatibility, and low toxicity. Natural biodegradable carrier materials include albumin, gelatine, soybean, collagen, and polysaccharides such as chitosan, agarose, dextran, hyaluronic acid, sodium alginate, carrageenan, and cyclodextrin. ${ }^{20-23}$ Among them, serum albumin nanoparticles have been widely studied and have many advantages: (1) serum albumin is an endogenous substance that is nontoxic, biodegradable, water-soluble, non-immunogenic, and good biocompatibility. (2) it has a good ability to accumulate in tumor sites; (3) its unique structure can significantly increase the solubility of hydrophobic drugs and reduce the side effects of drugs; and (4) it is easy to modify. ${ }^{24,25}$ The successful application and excellent efficacy of the commercially available formulation paclitaxel albumin nanosuspension demonstrates the clinical potential of albumin carriers. Albumin is classified into different types depending on the source, including ovalbumin (OVA), bovine serum albumin (BSA), and human serum albumin (HSA). Among them, BSA and HSA have been widely used as nano-drug carriers. ${ }^{26-28}$ The preparation method of albumin nanoparticles mainly includes the desolvation method, spray drying method, high-pressure homogenization method, salting out method, ultrasonic method, and so on. ${ }^{29-33}$ Most of these methods require the addition of organic solvents or cross-linking agents, which are not safe or environmentally friendly. Therefore, it is necessary to find a more suitable preparation method for albumin nanoparticles for better applications in drug delivery.

In this study, BSA was used as a nano-carrier material to construct CBZ-loaded BSA nanoparticles (CBZ-BSA-GdNPs) by biomineralization of the magnetic metal element gadolinium (Gd). The preparation method is simple and environmentally friendly without the use of an organic solvent or a cross-linking agent. Morevoer, because Gd is a contrast agent, CBZ-BSA-Gd-NPs can realize the integration of diagnosis and therapy. Then, the hemolysis of erythrocytes, and the inhibition and uptake of tumor cells in vitro, the pharmacokinetics, and tissue distribution in vivo, and the antitumor activity of CBZ-BSA-Gd-NPs in nude mice was evaluated comprehensively. The prepared CBZ-BSA-Gd-NPs can overcome the allergic reaction from Tween 80 and realize the integration of diagnosis and therapy of prostate cancer.

\section{Materials and Methods}

\section{Reagents}

$\mathrm{CBZ}, \mathrm{GdCl}_{3} \cdot 6 \mathrm{H}_{2} \mathrm{O}$, and Tween 80 were obtained from Dalian Meilun Biotech Co., Ltd. (Dalian, China). BSA was purchased from Biofroxx (Einhausen, Germany). Acetonitrile and methanol (high-performance liquid chromatography [HPLC]-grade) were obtained from Merck (Darmstadt, Germany). Other organic solvents were purchased from Sinopharm (Shanghai, China). RPMI-1640 medium, penicillin-streptomycin, trypsin, and phosphatebuffered saline (PBS) were obtained from Thermo Scientific HyClone (IL, USA). Foetal bovine serum (FBS) was purchased from Invitrogen (CA, USA).

\section{Cell Culture}

Human prostate cancer PC-3 and LNCAP cells were purchased from American Type Culture Collection (VA, USA) and maintained in a humidified atmosphere of $5 \%$ $\mathrm{CO}_{2}$ at $37^{\circ} \mathrm{C}$. The cells were cultured in RPMI- 1640 medium supplemented with $10 \% \mathrm{FBS}, 100 \mathrm{U} / \mathrm{mL}$ penicillin, and $100 \mu \mathrm{g} / \mathrm{mL}$ streptomycin. 


\section{Animals}

Sprague-Dawley (SD) rats (male, $220 \pm 20 \mathrm{~g}$ ) and BALB/c nude mice (male, 6 weeks) were purchased from the Shanghai Experimental Animal Center of the Chinese Academic of Sciences (Shanghai, China). All animal procedures were approved by the Committee on Animals of the Second Military Medical University. All animal procedures were performed in accordance with the guidelines of the Animal Committee of the Second Military Medical University for the Welfare of animals. Before use in experiments, the mice were allowed to acclimate for one week.

\section{Preparation of the CBZ-BSA-Gd-NPs}

CBZ-BSA-Gd-NPs were prepared by the biomineralization method. Briefly, $5 \mathrm{~mL}$ of $\mathrm{GdCl}_{3} \cdot 6 \mathrm{H}_{2} \mathrm{O}(0.4 \mathrm{mg} / \mathrm{mL})$ was slowly added to a solution of BSA $(1 \mathrm{mg} / \mathrm{mL})$ with stirring for $3 \mathrm{~min}$ (500 rpm). Then, $5 \mathrm{~mL}$ of sodium hydroxide solution $(0.2 \mathrm{mg} / \mathrm{mL})$ was added, followed by stirring at room temperature. Finally, a CBZ solution $(20 \mathrm{mg} / \mathrm{mL})$ dissolved in DMSO was added, and stirring continued for $30 \mathrm{~min}$.

\section{Characterization of CBZ-BSA-Gd-NPs}

The particle size and zeta potential of CBZ-BSA-Gd-NPs were determined by dynamic light scattering (DLS) using a Zetasizer Nano S (Malvern Instruments, UK). The morphology of the CBZ-BSA-Gd-NPs was evaluated by transmission electron microscopy (TEM). Briefly, one drop of the properly diluted suspension was deposited on a carbon-coated copper grid and negatively stained with a $1 \%$ phosphotungstic acid solution for $5 \mathrm{~min}$. After air-drying, the samples were imaged by TEM.

\section{In vitro Relaxometry}

Various concentrations of CBZ $(0.02,0.04,0.08,0.16$, and $0.32 \mathrm{mM}$, calculated as the concentration of $\mathrm{Gd}^{3+}$ ) were measured using a 3.0 T MRI system. The $\mathrm{T}_{1}$ (longitudinal relaxation time) and $T_{2}$ (transverse relaxation time) were measured, and the relaxation rates were calculated to evaluate the contrast agents.

\section{Stability Evaluation}

To study the stability of the nanoparticles in vitro, CBZ-BSA -Gd-NPs were added to PBS buffer. Then, the nanoparticles were placed at $37{ }^{\circ} \mathrm{C}$, and an aliquot of nanoparticles was taken at different time points $(0,1,2,4,6,8,12$, and $24 \mathrm{~h})$ to measure the particle size. The colloidal stability of the nanoparticles was reflected by the changes in their particle size.
To investigate the stability of the drug contained in the nanoparticles, the in vitro leakage rate of CBZ-BSA-Gd-NPs was determined by dialysis. CBZ-BSA-Gd-NPs $(0.5 \mathrm{~mL})$ were transferred into a dialysis bag (MWCO $14 \mathrm{kDa}$, Spectra/Por), which was immersed in $10 \mathrm{~mL}$ of PBS solution containing $30 \%$ isopropanol at $37^{\circ} \mathrm{C}$. At different time points, a $0.5 \mathrm{~mL}$ aliquot of release medium was removed to determine the amount of drug leakage into the medium.

\section{Hemolysis Assay}

To evaluate the hemolytic properties of CBZ-Tween 80 and CBZ-BSA-Gd-NPs, CBZ-Tween 80 (dissolved in Tween 80 and $13 \%[\mathrm{w} / \mathrm{w}]$ ethanol at a ratio of $15: 57[\mathrm{w} /$ w]) and different concentrations of CBZ-BSA-Gd-NPs (dissolved in $0.9 \%$ saline) were incubated in a suspension of red blood cells at $37{ }^{\circ} \mathrm{C}$ for $2 \mathrm{~h}$ and then centrifuged at $3000 \mathrm{rpm}$ for $10 \mathrm{~min}$. PBS and distilled water were used as a negative ( $0 \%$ lysis) and positive control $(100 \%$ lysis $)$, respectively. The supernatant was aspirated and the OD value was measured at a wavelength of $540 \mathrm{~nm}$ using a microplate reader. The hemolysis rate was calculated by the following formula:

$$
\text { Hemolysis rate }(\%)=\frac{\text { OD sample }- \text { OD negative }}{\text { OD positive }- \text { OD negative }}
$$

where $\mathrm{OD}_{\text {sample}}, \mathrm{OD}_{\text {negative, }}$ and $\mathrm{OD}_{\text {positive }}$ indicate the OD value of the samples, negative and positive controls, respectively.

\section{Cytotoxicity Assay}

The cytotoxicity of the nanoparticles in PC-3 and LNCAP cells was evaluated by a CCK- 8 assay. Briefly, PC-3 cells were seeded in 96-well plates and incubated overnight. The cells were then incubated with varying concentrations of CBZ-BSA-Gd-NPs, blank nanoparticles, CBZ-Tween 80 and Tween 80 for $24 \mathrm{~h}$. The cell viability was analysed by the CCK- 8 kit, and the absorbance was measured at $450 \mathrm{~nm}$.

\section{In vitro Cellular Uptake}

The cellular uptake of the nanoparticles into PC-3 and LANCAP cells was examined by flow cytometry. Briefly, PC-3 cells were seeded in 48-well plates at a density of $2.5 \times 10^{4}$ per well and incubated overnight. The cells were then treated with $1 \mu \mathrm{M}$ CBZ-BSA-Gd-NPs-FITC for 0.5 , 1,2 , and $4 \mathrm{~h}$. The cells were digested and incubated with $400 \mu \mathrm{L}$ of $4 \%$ formaldehyde solution for $10 \mathrm{~min}$. The amount of intracellular fluorescence was detected by flow cytometry to calculate the cellular uptake. 


\section{Pharmacokinetic Study}

Twelve SD rats (male, $220 \pm 20 \mathrm{~g}$ ) were randomly divided into two groups (six rats per group). The rats were fasted for $12 \mathrm{~h}$ before the test and were given free access to water. The rats were intravenously administered CBZTween 80 and CBZ-BSA-Gd-NPs at a CBZ dose of $8 \mathrm{mg} / \mathrm{kg}$. Three hundred microliters of plasma was collected from the fossa orbitalis vein into heparinized centrifuge tubes at $0.08,0.25,0.5,1,2,4,6,8,10,12,24$ and $48 \mathrm{~h}$, and centrifuged at $8000 \mathrm{rpm}$ for $10 \mathrm{~min}$. The supernatants were obtained and stored at $-20{ }^{\circ} \mathrm{C}$. All plasma samples were pre-treated as described below: $25 \mu \mathrm{L}$ of plasma sample was mixed with $25 \mu \mathrm{L}$ of internal standard (IS) solution (paclitaxel, $50 \mathrm{ng} / \mathrm{mL}$ ), $25 \mu \mathrm{L}$ of acetonitrile, $100 \mu \mathrm{L}$ of water and $800 \mu \mathrm{L}$ of methyl tert-butyl ether. After vortexing, the sample was centrifuged at $10,000 \mathrm{rpm}$ for $5 \mathrm{~min}$ at $4{ }^{\circ} \mathrm{C}$. Then, $800 \mu \mathrm{L}$ of the supernatant was dried under a nitrogen stream and resuspended in $150 \mu \mathrm{L}$ of acetonitrile for HPLC-MS/MS analysis. The plasma concentrations of $\mathrm{CBZ}$ was determined using an Agilent Technologies 1260 series LC/MS system (Agilent, USA) equipped with a Symmetry C18 column $(3.0 \times 100 \mathrm{~mm}$, $3.5 \mu \mathrm{m}$, Waters, USA). The mobile phase was composed of 40:60 (v/v) $0.1 \%$ aqueous formic acid/acetonitrile, and the flow rate was $0.8 \mathrm{~mL} / \mathrm{min}$, and the column temperature was maintained at $40^{\circ} \mathrm{C}$. Mass spectrometry conditions were as follows: ion source, electrospray ionization source (ESI source); detection method, positive ion detection; scanning method, multiple-reaction monitoring (MRM) mode; ion source temperature, $170{ }^{\circ} \mathrm{C}$; ion source gas 1 $\left(\mathrm{N}_{2}\right), 421.5 \mathrm{kPa}$; ion source gas $2\left(\mathrm{~N}_{2}\right), 486.4 \mathrm{kPa}$; and the MRM transitions were set at $836.4>555.2(\mathrm{~m} / \mathrm{z})$, and $854.3>486.1(\mathrm{~m} / \mathrm{z})$ for $\mathrm{CBZ}$ and the IS, respectively. Pharmacokinetic parameters were calculated using DAS software.

\section{In vivo Tissue Distribution}

PC-3 cells $\left(2 \times 10^{6} /\right.$ mouse $)$ were injected subcutaneously into $\mathrm{BALB} / \mathrm{C}$ nude mice (male, 6 weeks old, approximately $20 \mathrm{~g}$ ). When the tumor volume reached $150 \mathrm{~mm}^{3}$, the mice were randomly divided into three groups (six mice per group): saline, CBZ-Tween 80 and CBZ-BSAGd-NPs. All formulations were injected via the tail vein at a CBZ dose of $10 \mathrm{mg} / \mathrm{kg}$. At the time points of 1, 12, and $24 \mathrm{~h}$, mice were euthanized. Heart, liver, spleen, lung, kidney, and tumor samples were excised. The tissue samples were rinsed with saline, weighed, and stored at $-80^{\circ} \mathrm{C}$ until HPLC-MS analysis of CBZ.

\section{In vivo $M R I$}

The PC-3 cell-derived subcutaneous tumor model was established as described above. Five hundred microliters of a CBZ-BSA-Gd-NP suspension was injected via the tail vein at a dose of $0.1 \mathrm{mg} / \mathrm{kg} \mathrm{Gd}$. The coronal spin-echo T1weighted MRI images were acquired before and $1 \mathrm{~h}, 12 \mathrm{~h}$, and $24 \mathrm{~h}$ after administration using a 3.0 T MRI system equipped with a mouse imaging coil. The parameters were as follows: TR: $500 \mathrm{~ms}$; TE: $10 \mathrm{~ms}$; FOV: $100 \mathrm{~mm}$; slice thickness: $2 \mathrm{~mm}$; and NSA: 3 . The MR data were processed using ImageJ software.

\section{In vivo Antitumor Assays}

The in vivo antitumor activity of the nanoparticles was assessed in a PC-3 cell-derived subcutaneous tumor model as described above. The mice were randomly divided into three groups (six mice per group): saline, CBZ-Tween 80 and CBZ-BSA-Gd-NPs. At days 1, 3, 5, 7, and 9, all formulations were injected via the tail vein at a CBZ dose of $10 \mathrm{mg} / \mathrm{kg}$. Startig from the day of the first administration, the changes in body weight and tumor volume of the mice were measured every 3 days. The tumor volume was calculated with the following formula: tumor volume $=0.5 \times$ length $\times$ width $^{2}$. Additionally, the mice were sacrificed, and the heart, liver, spleen, lung, kidney, and tumor tissues were collected and stained with haematoxylin and eosin (H\&E) for histopathological examination.

\section{Statistical Analysis}

Data in this study were analysed using SPSS 18.0 software (SPSS, Inc., IL, USA). Statistical analysis was performed by Student's unpaired t-tests and ANOVA. ${ }^{*} \mathrm{P}<0.05 ; * * \mathrm{P}<0.01$.

\section{Results}

\section{Characterization of CBZ-BSA-Gd-NPs}

In this research, CBZ was successfully encapsulated into BSA nanoparticles through the biomineralization method. The particle size of CBZ-BSA-Gd-NPs was $166.3 \pm 4.2 \mathrm{~nm}$ with a PDI of 0.253 , and the zeta potential was $-18.21 \pm 1.08$ $\mathrm{mV}$ (Figure 1A). As demonstrated by the TEM image (Figure 1B), the morphology of CBZ-BSA-Gd-NPs was spherical. 


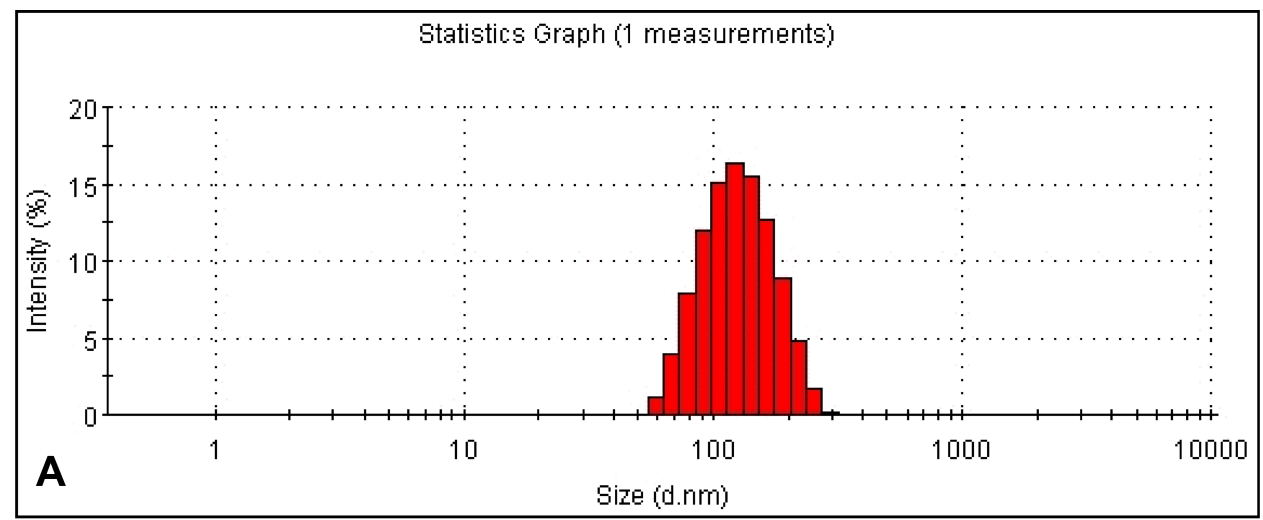

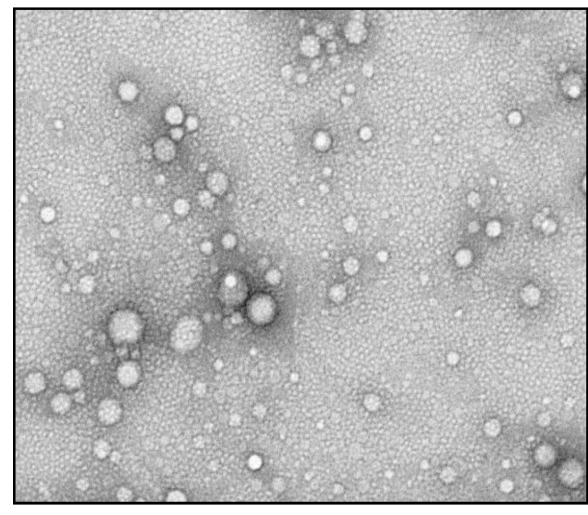

B

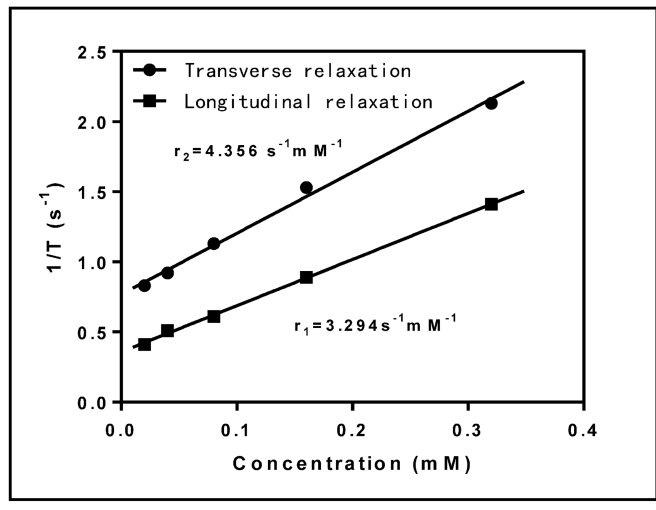

C

Figure I Characterization of CBZ-BSA-Gd-NPs. (A) The size distribution of CBZ-BSA-Gd-NPs as determined by DLS. (B) TEM image of CBZ-BSA-Gd-NPs. (C) Longitudinal relaxation rate $\left(r_{1}=1 / T_{1}\right)$ and tranversal relaxation rate $\left(r_{2}=1 / T_{2}\right)$ as a function of $G^{3+}$ concentration.

\section{In vitro Relaxometry}

To evaluate the relaxation of the nanoparticles, the longitudinal relaxation rate $\left(\mathrm{r}_{1}=1 / \mathrm{T}_{1}\right)$ and transverse relaxation rate $\left(r_{2}=1 / T_{2}\right)$ of the CBZ-BSA-Gd-NPs were determined (Figure 1C). The CBZ-BSA-Gd-NPs exhibited $r_{1}$ values of $3.294 \mathrm{~s}^{-1} / \mathrm{mM} \mathrm{Gd}^{3+}$ and $\mathrm{r}_{2}$ values of $4.356 \mathrm{~s}^{-1} / \mathrm{mM} \mathrm{Gd}^{3+}$, with a low $r_{2} / r_{1}$ ratio of 1.322 , which indicates high relaxation efficiency and is expected to be useful for tumor diagnosis and realize the integration of diagnosis and treatment.

\section{Stability Evaluation}

The stability of CBZ-BSA-Gd-NPs in PBS was investigated. As shown in Table 1 , after incubation at $37^{\circ} \mathrm{C}$ for $24 \mathrm{~h}$, the particle size was unchanged and maintained at approximately $170 \mathrm{~nm}$, which indicated that CBZ-BSAGd-NPs had good stability in PBS.

The results from the in vitro leakage test showed that the drug leakage rate was less than $5 \%$ within 6 h at $37^{\circ} \mathrm{C}$, indicating that CBZ-BSA-Gd-NPs were stable and compatible, and could be used for subsequent in vivo pharmacokinetic and pharmacodynamic studies.

\section{Hemolysis Assay}

To determine whether CBZ-BSA-Gd-NPs are safe for intravenous injection, a hemolysis assay was performed (Figure 2A). The hemolysis rate of CBZ-Tween 80 was higher than that of the CBZ-BSA-Gd-NPs, as the hemolysis rate of CBZ-BSA-Gd-NPs was less than $5 \%$ in the range of $0.01-0.5 \mathrm{mg} / \mathrm{mL}$, which means no hemolysis and meets the requirements of injection administration.

\section{Cytotoxicity Assay}

The CCK-8 method was used to determine the cytotoxicity of nanoparticles to PC-3 and LNCAP cells (Figure 2B and $\mathrm{C}$ ). The results showed that blank nanoparticles had

Table I Stability of CBZ-BSA-Gd-NPs in PBS at $37^{\circ} \mathrm{C}$

\begin{tabular}{|l|l|l|l|l|l|l|l|}
\hline $\begin{array}{l}\text { Time } \\
\text { (h) }\end{array}$ & $\mathbf{0}$ & $\mathbf{1}$ & $\mathbf{2}$ & $\mathbf{4}$ & $\mathbf{8}$ & $\mathbf{1 2}$ & $\mathbf{2 4}$ \\
\hline $\begin{array}{l}\text { Particle } \\
\text { size(nm) } \\
\text { PDI }\end{array}$ & 166.1 & 166.7 & 166.9 & 167.3 & 168.4 & 168.6 & 169.1 \\
\hline
\end{tabular}




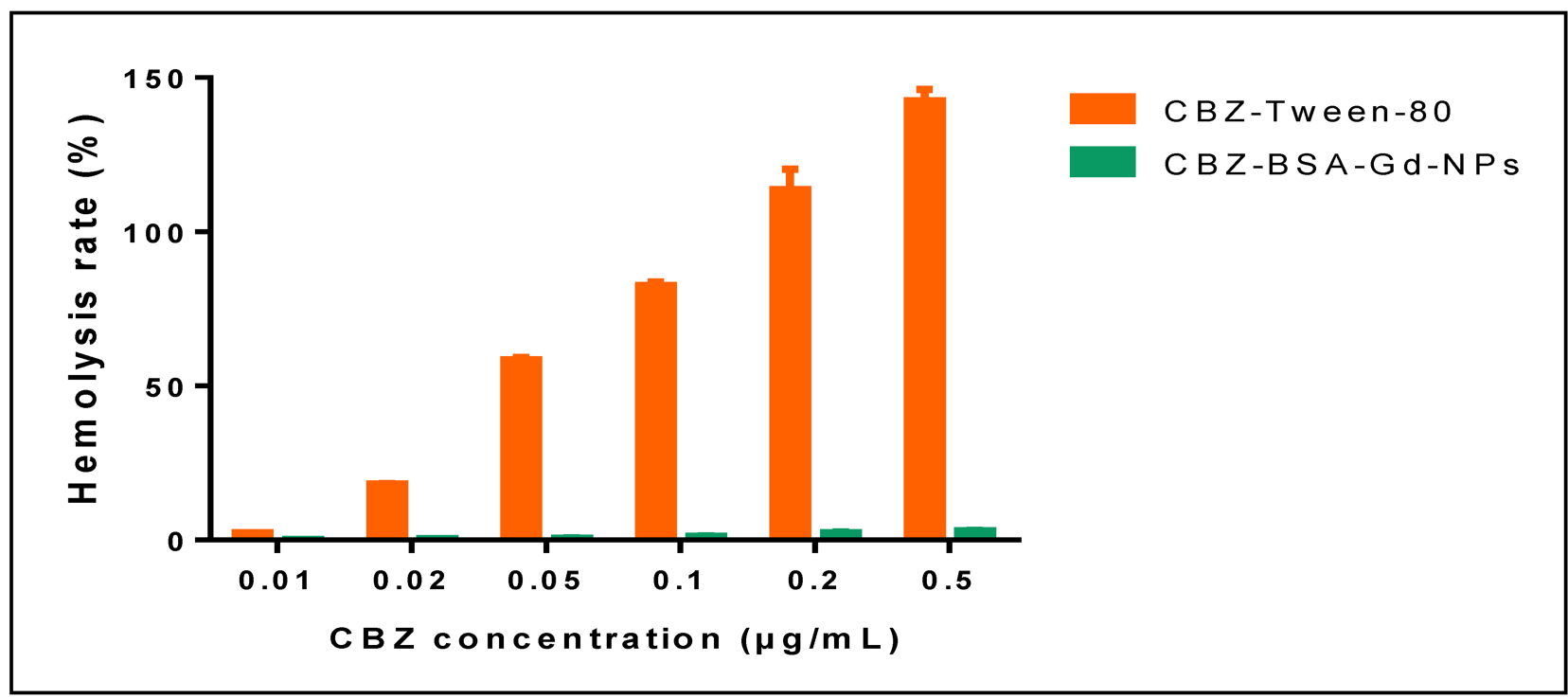

A

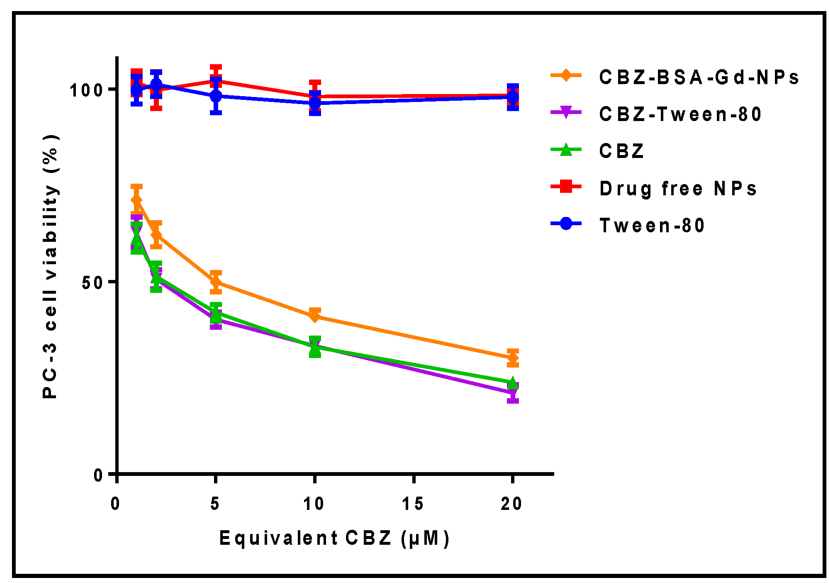

B
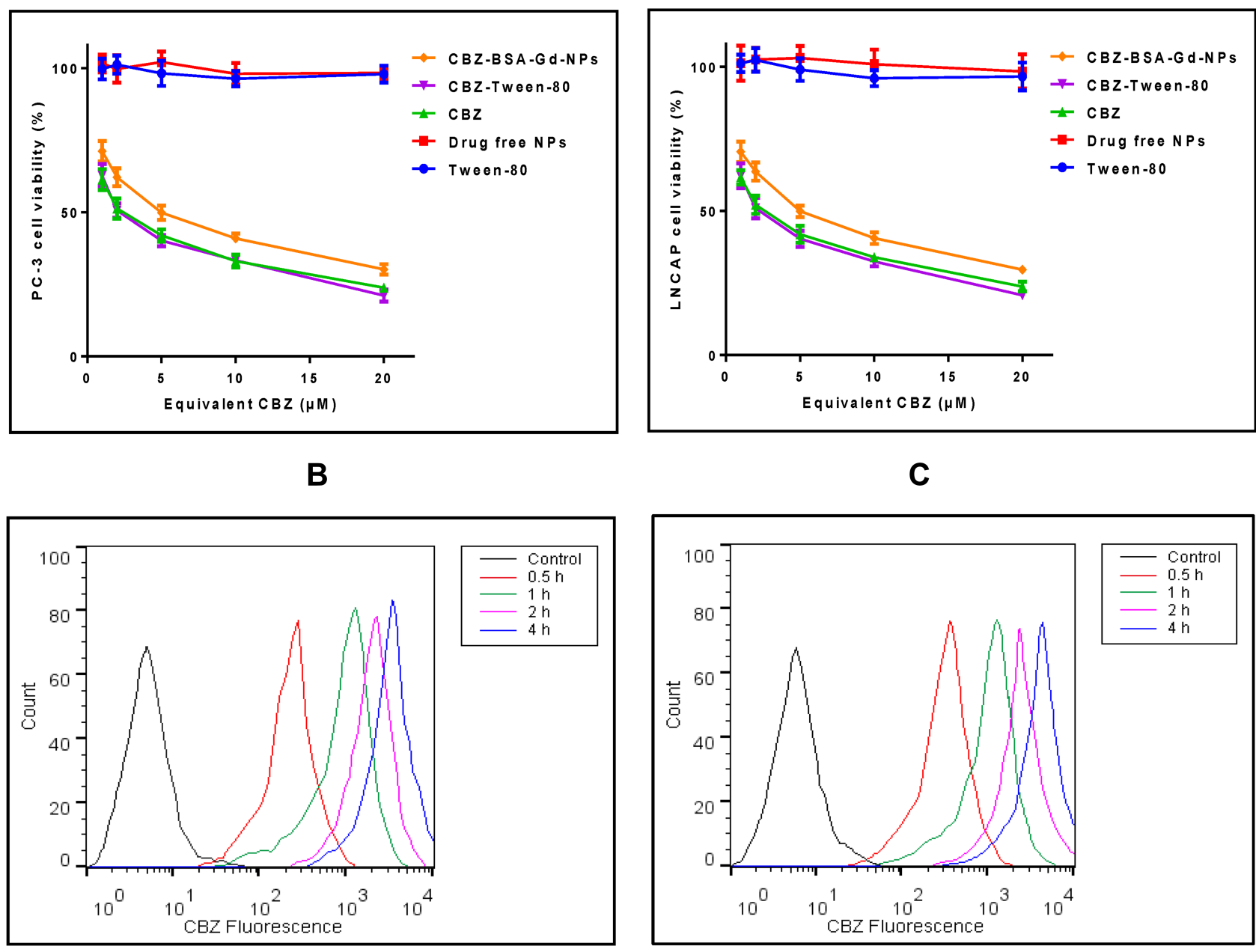

D

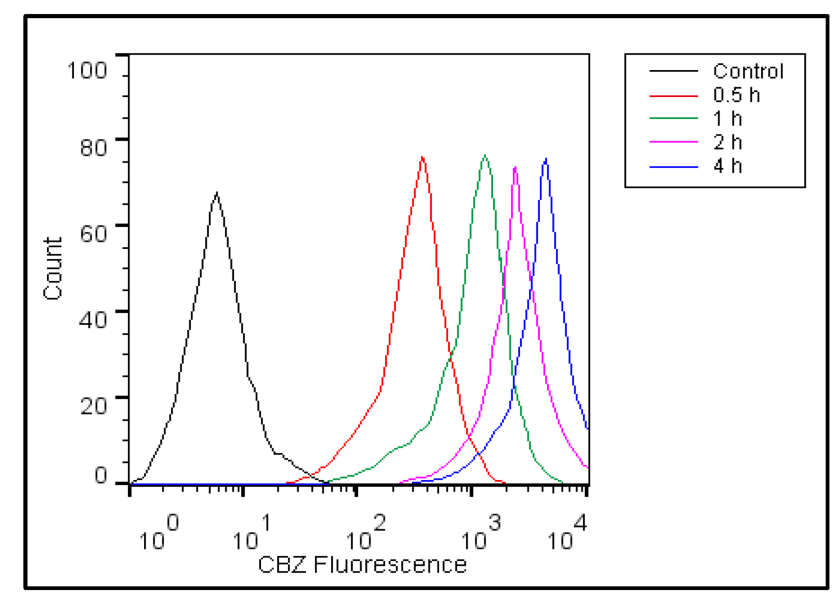

E

Figure 2 In vitro hemolysis assay, cytotoxicity and cell uptake of CBZ Tween 80 and CBZ-BSA-Gd-NPs. (A) hemolysis assay of CBZ Tween 80 and CBZ-BSA-Gd-NPs in a suspension of mice red blood cells; (B) cytotoxicity in PC-3 cell of CBZ Tween 80 and CBZ-BSA-Gd-NPs; (C) cytotoxicity in LNCAP cell of CBZ Tween 80 and CBZ-BSAGd-NPs; (D) cell uptake into PC-3 cell of CBZ Tween 80 and CBZ-BSA-Gd-NPs; (E) cell uptake into LNCAP cell of CBZ Tween 80 and CBZ-BSA-Gd-NPs; Data are presented as means \pm standard deviations $(n=3)$. 
no obvious cytotoxicity at the specified concentrations, indicating the safety of the drug delivery system. CBZ, CBZ-Tween-80, and CBZ-BSA-Gd-NPs had significant and similar inhibitory effects on PC-3 and LNCAP cells in a concentration-dependent manner, with $\mathrm{IC}_{50}$ values of $2.41 \pm 0.21 \mu \mathrm{M}, 2.38 \pm 0.38 \mu \mathrm{M}$, and $4.91 \pm 0.21 \mu \mathrm{M}$, respectively.

\section{In vitro Cellular Uptake}

To determine the cellular uptake of nanoparticles into PC3 and LNCAP cells, the fluorescence intensity in the cells was detected by flow cytometry (Figure 2D and E). PC-3 cells were treated with CBZ-BSA-Gd-NPs-FITC nanoparticles for $0.5,1,2$, and $4 \mathrm{~h}$, and the fluorescence intensity gradually increased when the incubation time increased, indicating that internalization occurred in a timedependent manner.

\section{Pharmacokinetic Study}

The plasma concentration-time curves for CBZ after administration of CBZ Tween 80 and CBZ-BSA-Gd-NPs are shown in Figure 3A. The plasma drug concentrations of CBZ Tween 80 and CBZ-BSA-Gd-NPs showed significant differences after intravenous administration for $5 \mathrm{~min} ; 3.087 \mu \mathrm{g} / \mathrm{mL}$ for CBZ Tween 80 versus $5.143 \mu \mathrm{g} / \mathrm{mL}$ for CBZ-BSA-Gd-NPs. During drug clearance, the drug clearance rate in the plasma of CBZ Tween 80 was faster, and no drug was detected after $8 \mathrm{~h}$, while the drug was still detectable in the plasma of the CBZ-BSA-Gd -NPs treatment group at $48 \mathrm{~h}$. This demonstrated that CBZBSA-Gd-NPs had a slower clearance rate and longer circulation time in vivo than CBZ-Tween 80 .

The two-compartment model was used to calculate the pharmacokinetic parameters, including the peak plasma concentration $\left(\mathrm{C}_{\max }\right)$, elimination half-life $\left(\mathrm{t}_{1 / 2}\right)$, area under the curve $\left(\mathrm{AUC}_{0 \sim \infty}\right)$, and mean residence time
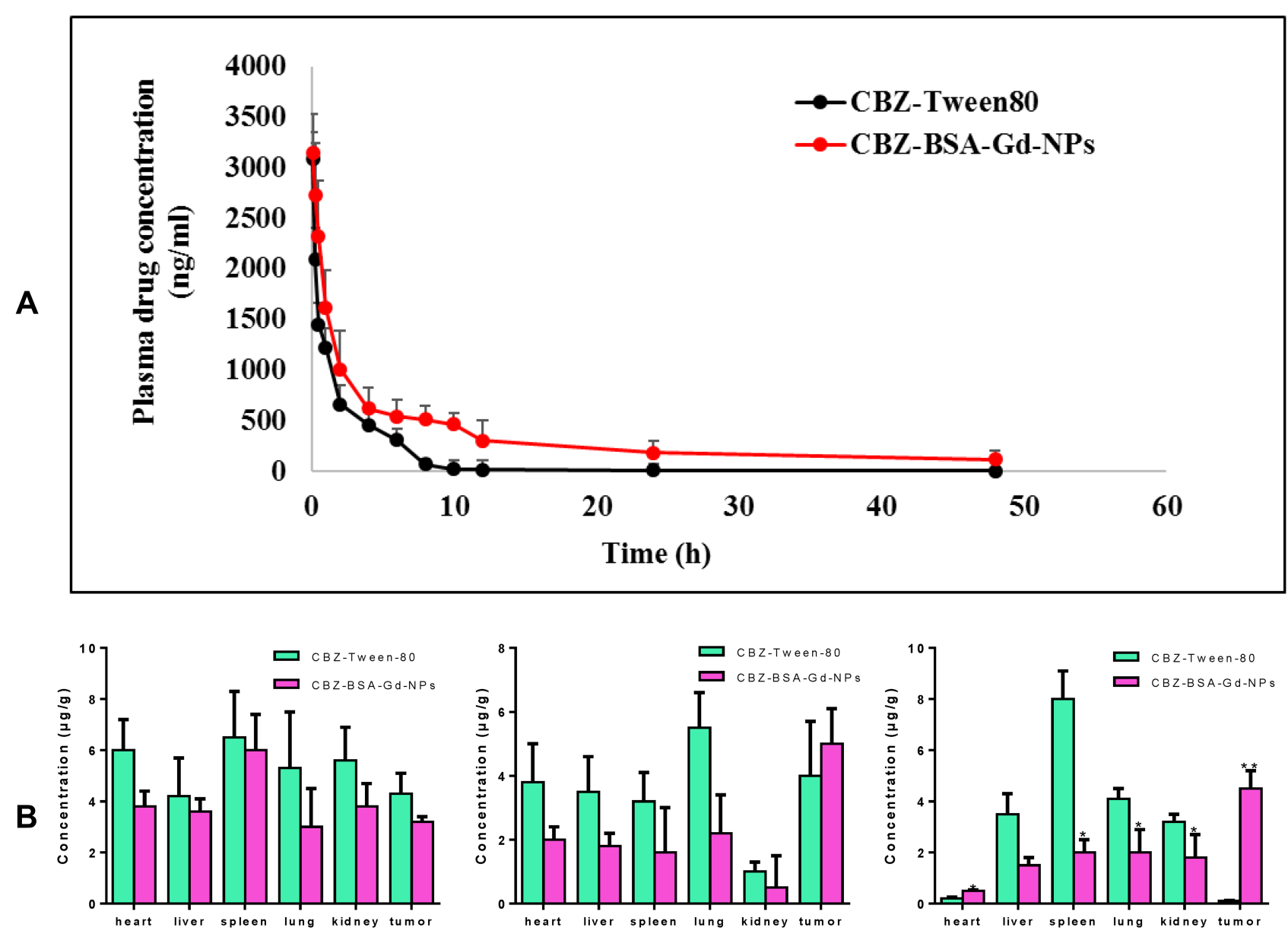

Figure 3 Pharmacokinetics and tissue distribution of CBZ after treatment with CBZ Tween 80 and CBZ-BSA-Gd-NPs at different time points. (A) The mean plasma concentration-time profiles for CBZ. (B) Tissue distribution of $C B Z$ at $1 \mathrm{~h}, 12 \mathrm{~h}$, and $24 \mathrm{~h}$ after administration. Data are presented as means \pm standard deviations $(\mathrm{n}=6)$. $* P<0.05, * * P<0.01$. 
Table 2 Pharmacokinetic Parameters of CBZ

\begin{tabular}{|l|l|l|l|}
\hline Parameters & Unit & CBZ Tween 80 & CBZ-BSA-Gd-NPs \\
\hline$t_{/ / 2}$ & $\mathrm{~h}$ & $14.76 \pm 2.31$ & $25.39 \pm 3.54^{\mathrm{a}}$ \\
$A U C_{0 \sim \infty}$ & $\mathrm{ng} / \mathrm{mL} \cdot \mathrm{h}$ & $10,896.93 \pm 109.63$ & $17,557.27 \pm 182.56^{\mathrm{a}}$ \\
$C_{\max }$ & $\mathrm{ng} / \mathrm{mL}$ & $3087.67 \pm 136.86$ & $3143.43 \pm 112.11$ \\
$\mathrm{CL}$ & $\mathrm{mL} / \mathrm{min} / \mathrm{kg}$ & $0.0014 \pm 0.0002$ & $0.0007 \pm 0.000013$ \\
$M R T_{0 \sim \infty}$ & $\mathrm{h}$ & $8.76 \pm 1.96$ & $13.24 \pm 2.88$ \\
\hline
\end{tabular}

Notes: ${ }^{a}$ CBZ-BSA-Gd-NPs v.s CBZ-Tween 80, $p<0.05(n=6)$.

$\left(\mathrm{MRT}_{0 \sim \infty}\right)$ (Table 2). Compared to CBZ-Tween 80, the $\mathrm{t}_{1 / 2}$ and $\mathrm{AUC}_{0 \sim \infty}$ values of CBZ-BSA-Gd-NPs were significantly higher $(\mathrm{P}<0.05)$, indicating a slower clearance rate and longer circulation time, which can lead to a higher plasma concentration and improve efficacy.

\section{In vivo Tissue Distribution}

The distribution of CBZ in the heart, liver, spleen, lung, kidney and tumor tissues at 1,12 , and $24 \mathrm{~h}$ after intravenous administration of CBZ-Tween 80 and CBZ-BSA-Gd-NPs at a dose of $10 \mathrm{mg} / \mathrm{kg}$ is shown in Figure 3B. Over time, the concentrations of CBZ in most organs after treatment with CBZ-BSAGd-NPs were significantly reduced. At the early time point of 1 $\mathrm{h}$, the concentration of CBZ in the tumors of mice treated with CBZ-BSA-Gd-NPs was lower than that after CBZ Tween 80 treatment. However, the drug concentration in the tumor tissue in the CBZ-BSA-Gd-NPs group was significantly higher 24 $\mathrm{h}$ post-injection. It was indicated that CBZ-BSA-Gd-NPs could not only avoid the allergic side effects caused by Tween- 80 but also passively target tumor tissue and release drugs slowly.

\section{In vivo $M R I$}

Since CBZ-BSA-Gd-NPs contain the contrast agent Gd, they can be used as a probe for MRI to evaluate the in vivo distribution of nanoparticles. MRI was performed at different time points after injecting CBZ-BSA-Gd-NPs via the tail vein (Figure 4). The results showed that the signal in the tumor area increased significantly after injection and gradually increased with time, reaching a peak at 12 h. This demonstrated that CBZ-BSA-Gd-NPs could play a diagnostic role in tumor therapy and realize the integration of diagnosis and treatment.

\section{In vivo Antitumor Assays}

The therapeutic efficacy of CBZ-BSA-Gd-NPs and CBZTween 80 was evaluated in a human prostate cancer xenograft model. The body weights and tumor volumes of the mice were monitored during treatment. The body weights of mice in each

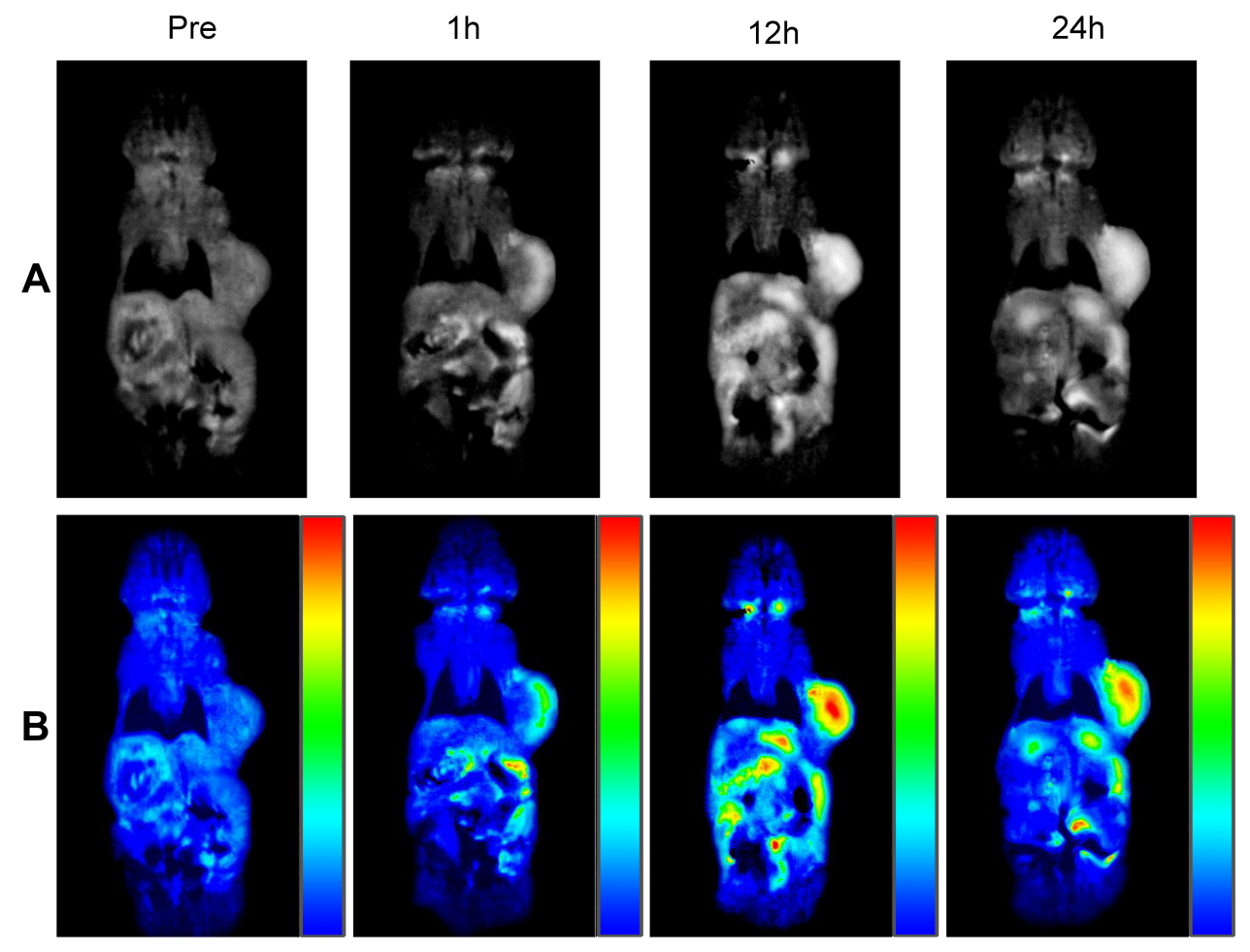

Figure 4 In vivo PC-3 tumor-bearing MRI. (A) TI-weighted MRI images of tumor-bearing mice. (B) TI-weighted MRI images processed by Image software. Images were collected at different times: pre injection, I h, $12 \mathrm{~h}$, and $24 \mathrm{~h}$ post-injection. 
group did not change significantly in the first three days. After 6 days, the body weight of each group began to decrease, and the weight loss of the CBZ-BSA-Gd-NP group was smaller than that of the CBZ Tween 80 group (Figure 5A). Both CBZBSA-Gd-NPs and CBZ Tween80 inhibited tumor growth. Moreover, CBZ-BSA-Gd-NPs had a stronger inhibitory effect on tumors than CBZ Tween 80 , which may be due to the prolonged retention time and sustained release of the drug, which increased the amount of drug accumulation at the tumor site (Figure 5B and C).The detailed tumor growth changes in three groups of mice after administration, including the median value and tumor range, are shown in the Supplemental Table 1. To further evaluate the safety of the nanoparticles, H\&E staining of heart, liver, spleen, lung, kidney and tumor sections of each treatment group was examined (Figure 6). CBZ-BSA-Gd-NPs had no significant differences in all tissues when compared to saline. These results demonstrated that CBZ-BSA-Gd-NPs had significant antitumor activity with minimal systemic toxicity in PC-3 xenografts.

\section{Discussion}

Prostate cancer is an androgen-dependent tumor that can be treated by traditional endocrine therapy. However, when the disease progresses to CRPC, traditional endocrine therapy fails and it is impossible to continue to effectively control prostate cancer. CBZ, a novel taxane antitumor drug, has a significant therapeutic effect on CRPC and is widely used in clinical practice. However, due to the addition of Tween-80, commercial CBZ injections have significant toxic side effects, requiring corticosteroid administration indicating the need to develop improved formulations. Therefore, in this study, CBZ-

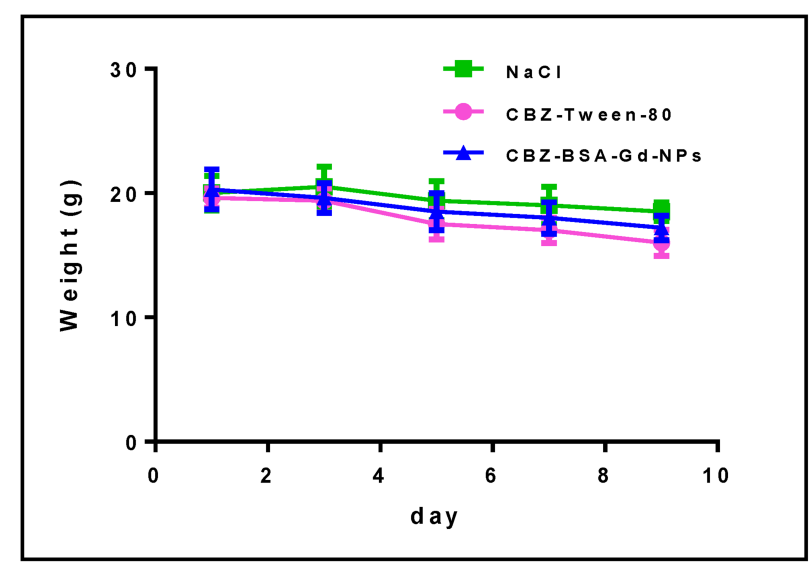

A

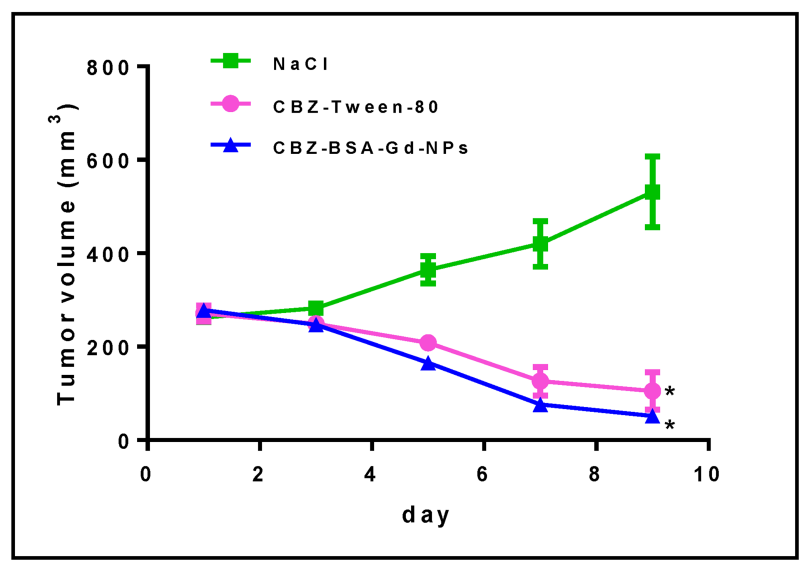

B

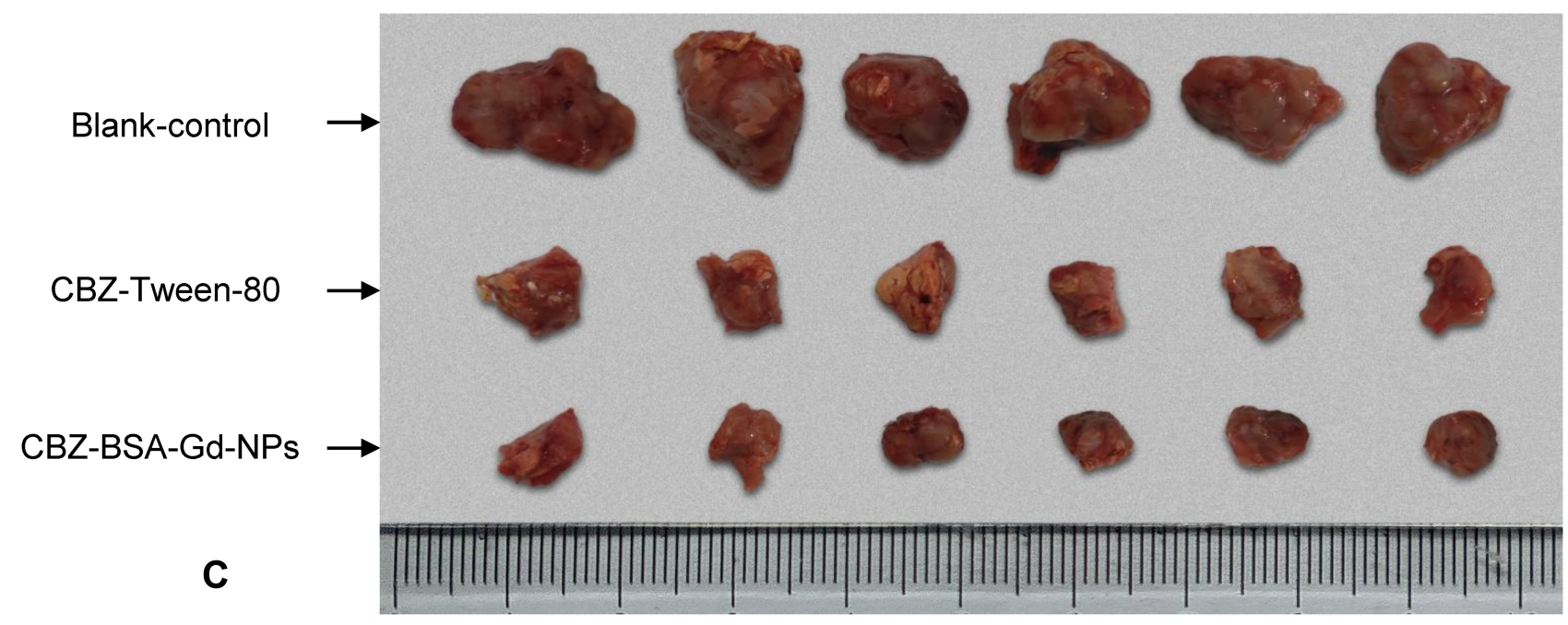

Figure 5 Antitumor activity of CBZ on prostate cancer tumor-bearing nude mice treated with intravenous injections of CBZ Tween 80 and CBZ-BSA-Gd-NPs (I0 mg/kg), saline was used as a control. (A) Body weights of the mice during the experiment. (B) Tumor growth curves. (C) The images of the excised tumor. Data are presented as means \pm standard deviations $(n=6)$. $* P<0.05$. 


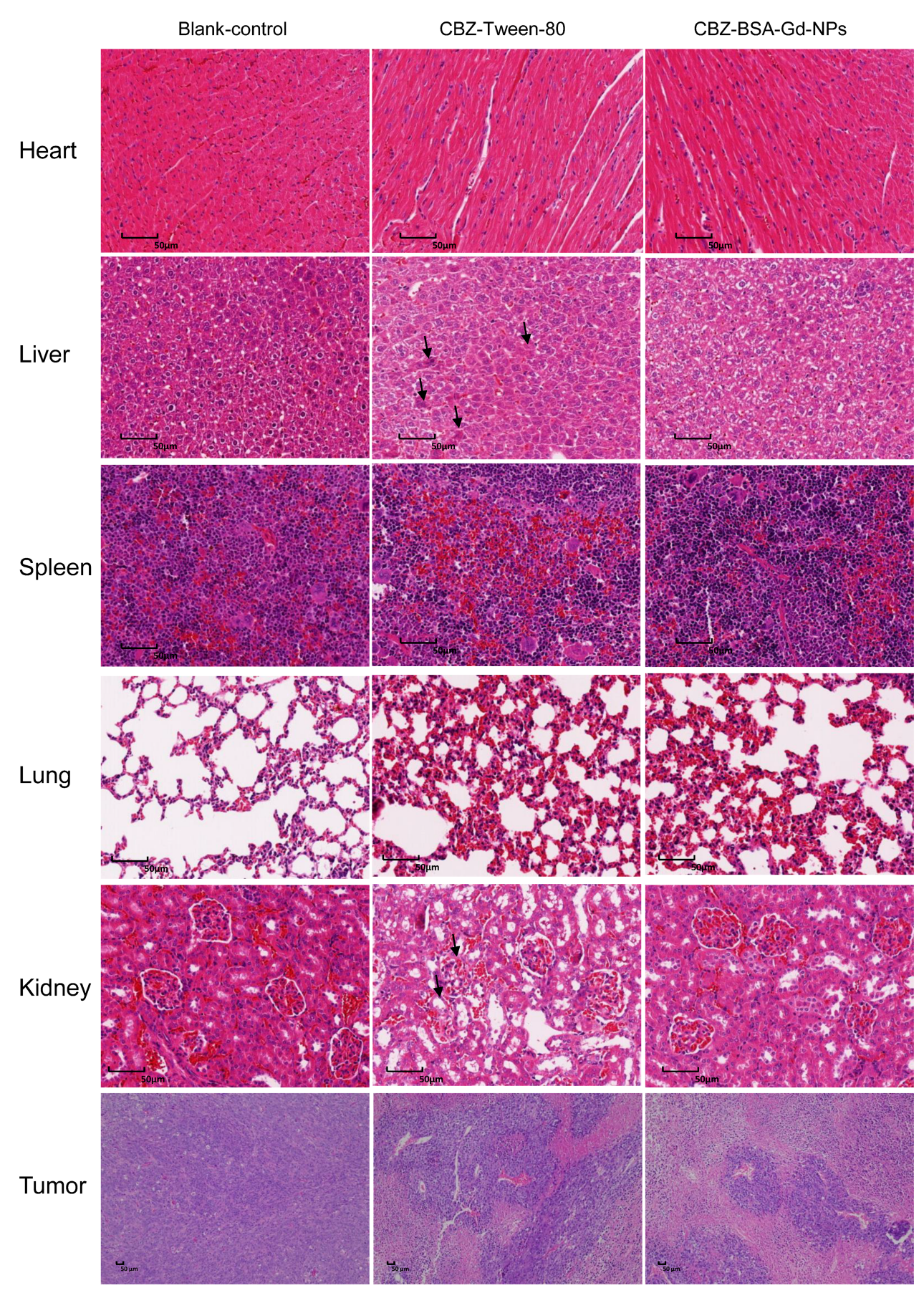

Figure $6 \mathrm{H} \& \mathrm{E}$ stained pathological sections of various organs on prostate cancer tumor-bearing nude mice treated with intravenous injections of CBZ Tween 80 and CBZBSA-Gd-NPs $(10 \mathrm{mg} / \mathrm{kg})$, saline was used as a control. Bars represent $50 \mu \mathrm{m}$ under $100 \mathrm{X}$ magnifier. Data are presented as means \pm standard deviations $(\mathrm{n}=6)$.

BSA-Gd-NPs were prepared to improve the water solubility and biocompatibility of CBZ.

At present, various nano-drug delivery systems have been used to reduce side effects and prolong the circulation time of CBZ, mainly including nanoparticles, micelles, and lipid microspheres. ${ }^{34-37}$ However, most of these studies are still in the basic research stages and cannot effectively achieve clinical transformation. Albumin nanoparticles have the advantages of safety, non-toxicity, and good biocompatibility. Moreover, Abraxane, which consists of albumin paclitaxel NPs, has already been widely used with success for the clinical treatment of breast cancer. Therefore, in this study, BSA was used to synthesize CBZ-BSA-Gd-NPs by the biomineralization of $\mathrm{Gd}^{3}$ ${ }^{+}$. The BSA-mediated biomineralization method has the advantages of simplicity, reproducibility, good biocompatibility and stability, and has good application prospects in clinical 
diagnosis and treatment. ${ }^{38}$ The prepared nanoparticles have a narrow particle size distribution and good stability. Additionally, blood compatibility of the drug carrier for intravenous injection is critical. Therefore, the in vitro haemolytic activity of CBZ-BSA-Gd-NPs was evaluated, and the results showed excellent blood biocompatibility, indicating that this formulation is suitable for intravenous administration. The pharmacokinetic results of the rats showed that CBZ-BSAGd-NPs had obvious sustained release characteristics compared to CBZ-Tween 80. The drug was encapsulated by nanoparticles, which prolonged the drug retention time in the body, reduced the clearance rate, and maintained a higher plasma concentration. All of these factors are conducive to the efficacy of the drug. In tissue distribution study, CBZ-BSAGd-NPs reduced the accumulation of drugs in the heart, liver, spleen, lung, and kidney, thereby reducing the toxicity in these organs. However, its accumulation in tumor tissues was been improved, mainly due to the passive targeting therapy of tumors by the EPR effect of the nanoparticles. Therefore, CBZ-BSA-Gd-NPs exhibited significant antitumor activity against PC-3 xenografts and had little effect on the body weights of the mice. Although albumin as a carrier has excellent biological properties in the nano-drug delivery system, its ability to target tumors needs to be further optimized. In our study, although CBZ-BSA-Gd-NPs improved the tumortargeting ability, which mainly relies on the passive targeting of albumin, there is still a certain distribution in the heart, liver, spleen, lung, and kidney. Therefore, further chemical modifications of albumin are needed to promote better targeting to tumors and exert an antitumor effect.

In addition, CBZ-BSA-Gd-NPs are expected to be used for tumor diagnosis due to the addition of the contrast agent $\mathrm{Gd}^{3+}$. Gd-DTPA is one of the most commonly used MRI contrast agents in the clinic with a certain T1 enhancement. The contrast agent based on $\mathrm{Gd}$ is a paramagnetic contrast agent, and the relaxation coefficient $\mathrm{r} 1$ can evaluate the contrast effect of the contrast agent to some extent. ${ }^{39,40}$ The relaxivity of CBZBSA-Gd-NPs was approximately $3.294 \mathrm{~s}^{-1} / \mathrm{mM}$, which was equivalent to that of Gd-DTPA $\left(3.246 \mathrm{~s} \mathrm{~s}^{-1} / \mathrm{mM}\right)$. Additionally, the transverse relaxivities of CBZ-BSA-Gd-NPs and GdDTPA were further measured to compare the $\mathrm{r} 2 / \mathrm{r} 1$ ratio. The r2/r1 ratios of CBZ-BSA-Gd-NPs and Gd-DTPA were found to be 1.322 and 1.372, respectively. Thus, CBZ-BSA-Gd-NPs could be used as a promising MRI agent due to their comparable $\mathrm{r} 2 / \mathrm{r} 1$ ratio to Gd-DTPA.

In summary, our results showed that CBZ-BSA-GdNPs could prolong the circulation time and reduce side effects, exhibiting excellent tumor targeting and antitumor activity compared to CBZ Tween 80 injection.

\section{Conclusion}

In this study, CBZ-BSA-Gd-NPs were prepared by the biomineralization method, which can overcome the allergic reaction of Tween 80 . Compared with CBZ-Tween 80 injection, CBZ-BSA-Gd-NPs have much lower hemolysis, similar tumor inhibition, enhanced cellular uptake in vitro and better pharmacokinetic behavior. CBZ-BSA-Gd-NPs not only had a passive targeting effect on tumor tissue but also achieved a better tumor inhibitory effect with a safer profile. Therefore, CBZ-BSA-Gd-NPs could serve as an effective therapeutic drug carrier to deliver CBZ into prostate cancer and have the potential to clinically diagnose and treat prostate cancer in the future.

\section{Disclosure}

The authors report no conflicts of interest in this work.

\section{References}

1. Siegel RL, Miller KD, Jemal A. Cancer statistics, 2019. CA Cancer J Clin. 2019;69(1):7-34. doi:10.3322/caac.21551

2. Crawford ED, Higano CS, Shore ND, et al. Treating patients with metastatic castration resistant prostate cancer: a comprehensive review of available therapies. J Urol. 2015;194(6):1537-1547. doi:10.1016/j.juro.2015.06.106

3. Abidi A. Cabazitaxel: a novel taxane for metastatic castration-resistantprostate cancer-current implications and future prospects. $J$ Pharmacol Pharmacother. 2013;4(4):230-237. doi:10.4103/0976-500X.119704

4. Jarvis C, Nelius T, Martinez-Marin D, et al. Cabazitaxel regimens inhibit the growth of prostate cancer cells and enhancesthe anti-tumor properties of PEDF with various effcacy and toxicity. Prostate. 2018;78(12):905-914. doi:10.1002/pros.23647

5. Paller CJ, Antonarakis ES. Cabazitaxel: a novel second-line treatment for metastatic castration-resistant prostate cancer. Drug Des Devel Ther. 2011;2011(5):117-124.

6. Onstenk W, Sieuwerts AM, Kraan J, et al. Efficacy of cabazitaxel in castration-resistant prostate cancer is independent of the presence of AR-V7 in circulating tumor cells. Eur Urol. 2015;68(6):939-945. doi:10.1016/j.eururo.2015.07.007

7. Moriceau G, Guillot A, Pacaut C, et al. Translating clinical evidencebased medicine into the real world: single-center experience withcabazitaxel in metastatic prostate cancer patients. Chemotherapy. 2016;61(3):127-133. doi:10.1159/000441379

8. Hoang B, Ernsting MJ, Tang WS, et al. Cabazitaxel-conjugated nanoparticles for docetaxel-resistant and bone metastatic prostate cancer. Cancer Lett. 2017;410:169-179. doi:10.1016/j.canlet.2017. 09.029

9. Hongo H, Kosaka T, Oya M. Analysis of cabazitaxel-resistant mechanism in human castration-resistant prostate cancer. Cancer Sci. 2018;109(9):2937-2945. doi:10.1111/cas.13729

10. Oudard S, Fizazi K, Sengelov L, et al. Cabazitaxel versus docetaxel as first-line therapy for patients with metastatic castration-resistant prostate cancer: arandomized phase $\amalg$ trial-FIRSTANA. $J$ Clin Oncol. 2017;35(28):3189-3197. doi:10.1200/JCO.2016.72.1068 
11. Zhuang B, Du L, Xu H, et al. Self-assembled micelle loading cabazitaxel for therapy of lung cancer. Int J Pharm. 2016;499(1-2):146-155. doi:10.1016/j.ijpharm.2015.12.073

12. He Z, Schulz A, Wan X, et al. Poly(2-oxazoline) based micelles withhigh capacity for 3rd generation taxoids: preparation, in vitro and in vivoevaluation. $J$ Control Release. 2015;208:67-75. doi:10.1016/j.jconrel.2015.02.024

13. Coors EA, Seybold H, Merk HF, Mahler V. Polysorbate 80 in medicalproducts and nonimmunologic anaphylactoid reactions. Ann AllergyAsthma Immunol. 2005;95(6):593-599. doi:10.1016/S10811206(10)61024-1

14. Ojima I, Lichtenthal B, Lee S, Wang C, Wang X. Taxane anticanceragents: a patent perspective. Expert Opin Ther Pat. 2016;26 (1):1-20. doi:10.1517/13543776.2016.1111872

15. Clèment-Zhao A, Auvray M, Aboudagga $H$, et al. Safety and efficacy of 2-weekly cabazitaxel in metastatic castration-resistant prostate cancer. BJU Int. 2018;121(2):203-208. doi:10.1111/bju.13855

16. Norouzi M, Amerian M, Amerian M, Atyabi F. Clinical applications of nanomedicine in cancer therapy. Drug Discov Today. 2019;pii: S1359-6446(19)30377-0.

17. Pérez-Herrero E, Fernández-Medarde A. Advanced targeted therapies in cancer: drug nanocarriers, the future of chemotherapy. Eur J Pharm Biopharm. 2015;93:52-79. doi:10.1016/j.ejpb.2015.03.018

18. Aftab S, Shah A, Nadhman A, et al. Nanomedicine: an effective tool in cancer therapy. Int J Pharm. 2018;540(1-2):132-149. doi:10.1016/ j.ijpharm.2018.02.007

19. Patra JK, Das G, Fraceto LF, et al. Nano based drug delivery systems: recent developments and future prospects. J Nanobiotechnology. 2018;16(1):71. doi:10.1186/s12951-018-0392-8

20. An FF, Zhang XH. Strategies for preparing albumin-based nanoparticles for multifunctional bioimaging and drug delivery. Theranostics. 2017;7(15):3667-3689. doi:10.7150/thno.19365

21. Foox M, Zilberman M. Drug delivery from gelatin-based systems. Expert Opin Drug Deliv. 2015;12(9):1547-1563. doi:10.1517/ 17425247.2015.1037272

22. Luo L, Wu Y, Liu C, et al. Designing soluble soybean polysaccharides-based nanoparticles to improve sustained antimicrobial activity of nisin. Carbohydr Polym. 2019;225:115251. doi:10.1016/j.carbpol.2019.115251

23. Zinger A, Koren L, Adir O, et al. Collagenase nanoparticles enhance the penetration of drugs into pancreatic tumors. ACS Nano. 2019;13 (10):11008-11021. doi:10.1021/acsnano.9b02395

24. Hoogenboezem EN, Duvall CL. Harnessing albumin as a carrier for cancer therapies. Adv Drug Deliv Rev. 2018;130:73-89. doi:10.1016/ j.addr.2018.07.011

25. Kratz F. A clinical update of using albumin as a drug vehicle - a commentary. J Control Release. 2014;190:331-336. doi:10.1016/j. jconrel.2014.03.013

26. Ma N, Liu J, He W, et al. Folic acid-grafted bovine serum albumin decorated graphene oxide: an efficient drug carrier for targeted cancer therapy. J Colloid Interface Sci. 2017;490:598-607. doi:10.1016/j. jcis.2016.11.097

International Journal of Nanomedicine

\section{Publish your work in this journal}

The International Journal of Nanomedicine is an international, peerreviewed journal focusing on the application of nanotechnology in diagnostics, therapeutics, and drug delivery systems throughout the biomedical field. This journal is indexed on PubMed Central, MedLine, CAS, SciSearch ${ }^{\circledR}$, Current Contents ${ }^{\mathbb{B}} /$ Clinical Medicine,
27. Wang J, Zhang B. Bovine serum albumin as a versatile platform for cancer imaging and therapy. Curr Med Chem. 2018;25 (25):2938-2953. doi:10.2174/0929867324666170314143335

28. Liu L, Bi Y, Zhou M, et al. Biomimetic human serum albumin nanoparticle for efficiently targeting therapy to metastatic breast cancers. ACS Appl Mater Interfaces. 2017;9(8):7424-7435. doi:10.1021/acsami.6b14390

29. Jahanban-Esfahlan A, Dastmalchi S, Davaran S. A simple improved desolvation method for the rapid preparation of albumin nanoparticles. Int J Biol Macromol. 2016;91:703-709. doi:10.1016/ j.ijbiomac.2016.05.032

30. Lee SH, Heng D, Ng WK, Chan HK, Tan RB. Nano spray drying: a novel method for preparing protein nanoparticles for protein therapy. Int $J$ Pharm. 2011;403(1-2):192-200. doi:10.1016/j. ijpharm.2010.10.012

31. Lomis N, Westfall S, Farahdel L, Malhotra M, Shum-Tim D, Prakash S. Human serum albumin nanoparticles for use in cancer drug delivery: process optimization and in vitro characterization. Nanomaterials (Basel). 2016;6(6):116. doi:10.3390/nano6060116

32. Qu N, Sun Y, Li Y, et al. Docetaxel-loaded human serum albumin (HSA) nanoparticles: synthesis, characterization, and evaluation. Biomed Eng Online. 2019;18(1):11. doi:10.1186/s12938-019-0624-7

33. Qu N, Lee RJ, Sun Y, et al. Cabazitaxel-loaded human serum albumin nanoparticles as a therapeutic agent against prostate cancer. Int J Nanomedicine. 2016;11:3451-3459. doi:10.2147/IJN.S105420

34. Gdowski AS, Ranjan A, Sarker MR, Vishwanatha JK. Bone-targeted cabazitaxel nanoparticles for metastatic prostate cancer skeletal lesions and pain. Nanomedicine(Lond). 2017;12(17):2083-2095. doi:10.2217/nnm-2017-0190

35. Aydin O, Youssef I, Yuksel Durmaz Y, Tiruchinapally G, ElSayed ME. Formulation of acid-sensitive micelles for delivery of cabazitaxel into prostate cancer cells. Mol Pharm. 2016;13 (4):1413-1429. doi:10.1021/acs.molpharmaceut.6b00147

36. Han X, Chen D, Sun J, et al. A novel cabazitaxel-loaded polymeric micelle system with superior in vitro stability and long blood circulation time. $J$ Biomater Sci Polym Ed. 2016;27(7):626-642. doi:10.1080/09205063.2016.1146980

37. Liu Y, Xie B, Li L, et al. PEGylated lipid microspheres loaded with cabazitaxel for intravenous administration: stability,bioavailability, antitumor efficacy,and toxicity. Drug Deliv Transl Res. 2018;8 (5):1365-1379. doi:10.1007/s13346-018-0562-0

38. Wang Y, Yang T, Ke H, et al. Smart albumin-biomineralized nanocomposites for multimodal imaging and photothermal tumor ablation. Adv Mater. 2015;27(26):3874-3882. doi:10.1002/adma.201500229

39. Bridot JL, Faure AC, Laurent S, et al. Hybrid gadolinium oxide nanoparticles: multimodal contrast agents for in vivo imaging. $J \mathrm{Am}$ Chem Soc. 2007;129(16):5076-5084. doi:10.1021/ja068356j

40. Wang Q, Lv L, Ling Z, et al. Long-circulating iodinated albumin-gadolinium nanoparticles as enhanced magnetic resonance and computed tomography imaging probes for osteosarcoma visualization. Anal Chem. 2015;87(8):4299-4304. doi:10.1021/ac504752a
Journal Citation Reports/Science Edition, EMBase, Scopus and the Elsevier Bibliographic databases. The manuscript management system is completely online and includes a very quick and fair peer-review system, which is all easy to use. Visit http://www.dovepress.com/
testimonials.php to read real quotes from published authors. 